\title{
Multiple vibration displacements at multiple vibration frequencies stress impact on human femur computational analysis
}

\author{
Bertram Ezenwa, PhD; ${ }^{*}$ Han Teik Yeoh, PhD \\ College of Health Sciences, University of Wisconsin-Milwaukee, Milwaukee, WI
}

\begin{abstract}
Whole-body vibration training using single-frequency methods has been reported to improve bone mineral density. However, the intensities can exceed safe levels and have drawn unfavorable comments from subjects. In a previous article, wholebody vibration training using multiple vibration displacements at multiple vibration frequencies (MVDMVF) was reported. This article presents the computational simulation evaluation of stress dispersion on a femur with and without the MVDMVF input. A model of bone femur was developed from a computed tomography image of the lower limb with Mimics software from Materialise (Plymouth, Michigan). We analyzed the mesh model in COMSOL Multiphysics (COMSOL, Inc; Burlington, Massachusetts) with and without MVDMVF input, with constraints and load applied to the femur model. We compared the results with published joint stresses during walking, jogging, and stair-climbing and descending and with standard vibration exposure limits. Results showed stress levels on the femur are significantly higher with MVDMVF input than without. The stress levels were within the published levels during walking and stair-climbing and descending but below the stress levels during jogging. Our computational results demonstrate that MVDMVF generates stress level equivalent to the level during walking and stair-climbing. This evidence suggests that MVDMVF is safe for prolonged use in subjects with osteoporosis who ambulate independently.
\end{abstract}

Key words: acceleration, BMD, bone, computation, femur, MVDMVF, osteoporosis, simulation, stress distribution, vibration training.

\section{INTRODUCTION}

Osteoporosis is a disease characterized by low bone mass and structural deterioration of bone tissue leading to bone fragility and an increased risk of hip, spine, and wrist fractures [1-4]. Osteoporosis-related fractures produce major morbidity [1-4] and are extremely common in older adults [5-6]. Annually, in the United States, about 1.5 million osteoporosis-related fractures occur, and this number is expected to increase about 50 percent by 2025 [7]. Three common key risk factors for osteoporosis are age, immobility, and being postmenopausal women with low body weight. Hip fractures are generally a fracture of the proximal femur and are responsible for the most serious consequences of osteoporosis [8]. Persons can reduce fracture risk by maintaining bone strength and supporting rapid bone remodeling. To reach these goals, persons with diabetes and elderly people use physical exercise regimes to reduce the risk for osteoporosis and fractures [9-10]. However, immobility, age, and other frailty may prevent optimal participation in exercise regimes designed for osteoporosis patients [11]. Reports indicate that mechanical stimulus in the form of vibration stimulus that travels from the sole of the foot up through the skeleton is anabolic to bone [12-14]. Some articles on current vibration

\footnotetext{
Abbreviations: $\mathrm{BMD}=$ bone mineral density, $\mathrm{CT}=$ computed tomography, ISO = International Organization for Standardization, MVDMVF = multiple vibration displacements at multiple vibration frequencies.

*Address all correspondence to Bertram Ezenwa, PhD; University of Wisconsin-Stout Discovery Center, Rm 123E STEM College, 712 S Broadway, Menomonie, WI 54751; 715-2325372; fax: 715-232-1105. Email: Eezenwa@uwP .edu

DOI:10.1682/JRRD.2010.05.0096
} 
devices have shown beneficial increases in bone mineral density (BMD) [15-16]; improvements in posture [1718], balance and gait [18-20], and skin blood flow [2123]; and positive impact on muscle activities, strength, and exercise outcomes [24-28].

Common to current vibration devices is the use of single fixed-vibration frequency and displacement height. The vibration parameters can be changed and fixed at a different level before the start of any session. The following paragraphs detail the main differences between current vibration devices and the multiple vibration displacements at multiple vibration frequencies (MVDMVF) in this study.

\section{Background}

Muscle fibers that contract rapidly are known as fasttwitch fibers. Others that contract slowly are known as slow-twitch fibers. Although a motor unit consists of only one kind of fiber type, most muscles have both fast- and slow-twitch fibers. The muscle fiber fast-twitch minimum frequency ranges from 40 to $60 \mathrm{~Hz}$ [29-30] and the slowtwitch minimum frequency from 15 to $30 \mathrm{~Hz}$ [31].

The amplitude of a mechanical vibration system is the characteristic that describes the severity of the mechanical energy content of a vibration input. For human muscle, the excitation frequency or frequencies of a mechanical vibration system are the characteristic that describes the muscle fiber type or types that can be elicited optimally at the twitch frequency by a vibration input. When a muscle fiber is excited at the twitch frequency, the innervated muscle contracts fully and exerts contraction energy on the attached bone. The energies contributed by the mechanical vibration and the induced muscle contraction together are responsible for the total stress on the human bone during whole-body vibration.

\section{Excitation Frequency Factor}

On one hand, single-frequency vibration systems operating within the muscle slow-twitch frequency will deliver the mechanical energy content of the vibration input plus the contraction energy of slow-twitch fibers. When the frequency is set within the muscle fiber fasttwitch frequency, the mechanical energy content of the vibration input plus the contraction energy of fast-twitch fibers will be exerted on the bone. On the other hand, MVDMVF operates at a frequency range that encompasses the muscle fiber slow-twitch frequency and fasttwitch frequency from 20 to $130 \mathrm{~Hz}$ and, therefore, will deliver the mechanical energy content of the vibration input plus the combined contraction energy of both slowand fast-twitch fibers on the bone. We consider the multiple vibration frequency of the MVDMVF to be more optimal than the single frequency of the counterpart because when people walk or run, both muscle fiber types are engaged.

\section{Mechanical Input Form Factor}

The principle behind single-frequency mechanical input form is similar to a seesaw about a center fulcrum, resulting in sine wave oscillations. Changing the frequency only changes the muscle fiber type to be recruited. The principle behind MVDMVF mechanical input form is quantum scatter derived from the brief contacts that cam peaks make with the telescoping platform. The ascent and descent were specifically engineered so that the telescoping platform exhibits a frequency response of 20 to $130 \mathrm{~Hz}$.

The fixed frequency method favors optimal excitation of single-muscle fiber types with twitch (resonant) frequency close to the device-operating frequency for recruiting intact muscle. However, human musculature is innervated with fibers of different twitch frequencies [32]. The minimum twitch frequency of fast-twitch fibers is reported to range from 40 to $60 \mathrm{~Hz}[29,30]$, and the minimum twitch frequency of slow-twitch fibers is reported to range from 15 to $30 \mathrm{~Hz}$ [31]. Logically, a vibration device that provides multiple vibration input frequencies that encompass all muscle fiber twitch frequencies will provide more enhanced intact muscle group recruitment than a single-frequency alternative and provide more benefit during vibration training. Such a device with output frequency from 20 to $130 \mathrm{~Hz}$ has been developed, and single-subject test results have been reported in the literature [33].

Stress fracture of the bone from impact forces is a major safety issue with the application of vibration stress in persons with osteoporosis and the elderly population with bone fragility. Bone is a living tissue requiring regular mechanical stress stimulation to maintain its mass [34], and applying low-level stress to bone will not have adverse effects [35]. However, applying high stresses may immediately or cumulatively damage bone [36]. From human subject experimental studies alone, fully discerning the pathway of mechanical stimulus transmission through the skeletal system during vibration training or quantifying the stress levels is difficult. Our main objective of this study is to evaluate stress transmission pathways and stress levels of vibration training with the use of computational simulation technique 
with a femur model derived from computed tomography (CT) images of the lower limb.

The rationale for the computational study of the impact of the MVDMVF device on the skeletal system is to impose various stress levels on the isolated human skeletal system without causing injury. We compare the results with published stress levels on the femur during human daily activities considered safe for persons with fragile bones to determine the safety factor of the MVDMVF device in the elderly population and people with osteoporosis.

\section{METHODS}

\section{Vibration System}

We used the MVDMVF device shown in Figure 1 to generate the multiple vibration intensities used for the computational simulation studies. We postulate that the MVDMVF device can provide a safe stress level to the musculoskeletal system to improve BMD irrespective of an individual's age. This hypothesis is based on three factors that will support the use of MVDMVF in a wider population:

1. Multiple vibration frequency modality will energize more muscle fiber types and recruit muscle groups more efficiently than single-frequency modality during any vibration session.

2. Overall stress from efficient muscle group recruitment does not require device-exaggerated vibration displacement levels for delivering beneficial effects.

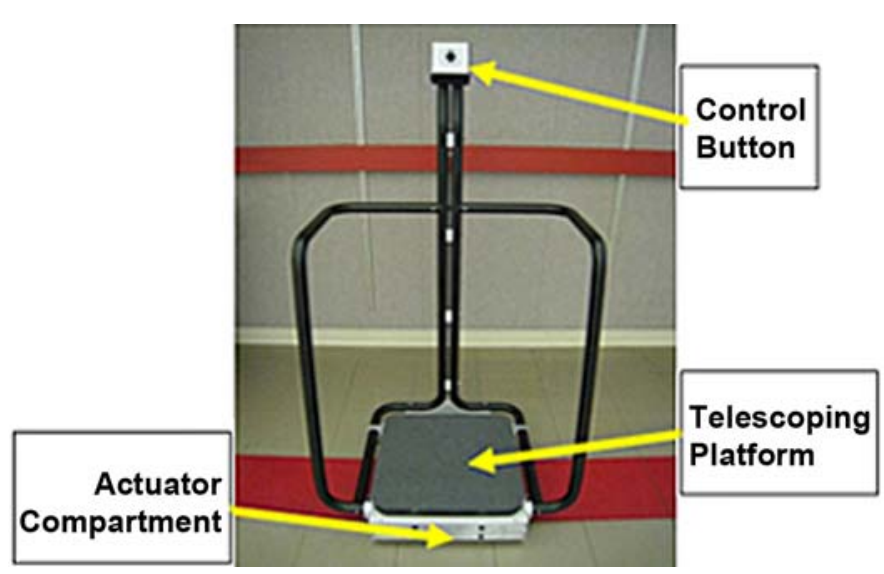

Figure 1.

Multiple vibration displacements at multiple vibration frequencies device.
3. Adequate stress to the bones for efficient delivery of bone mineral nutrients would shorten vibration application time for improving BMD benefits.

Specifically, the multiple intensities of the device platform in Figure 1 are derived from brief platform contacts with specially designed cams, illustrated in Figure 2(a). The cam geometry is iteratively experimentally validated so that the ascent to the peaks and descent to the troughs are achieved smoothly, and the frequency response of the platform is band-limited. These characteristics have been previously reported [33]. As is shown in Figure 2(b), four cams are strategically assembled out of phase on two shafts for asynchronously actuating the platform vibration during

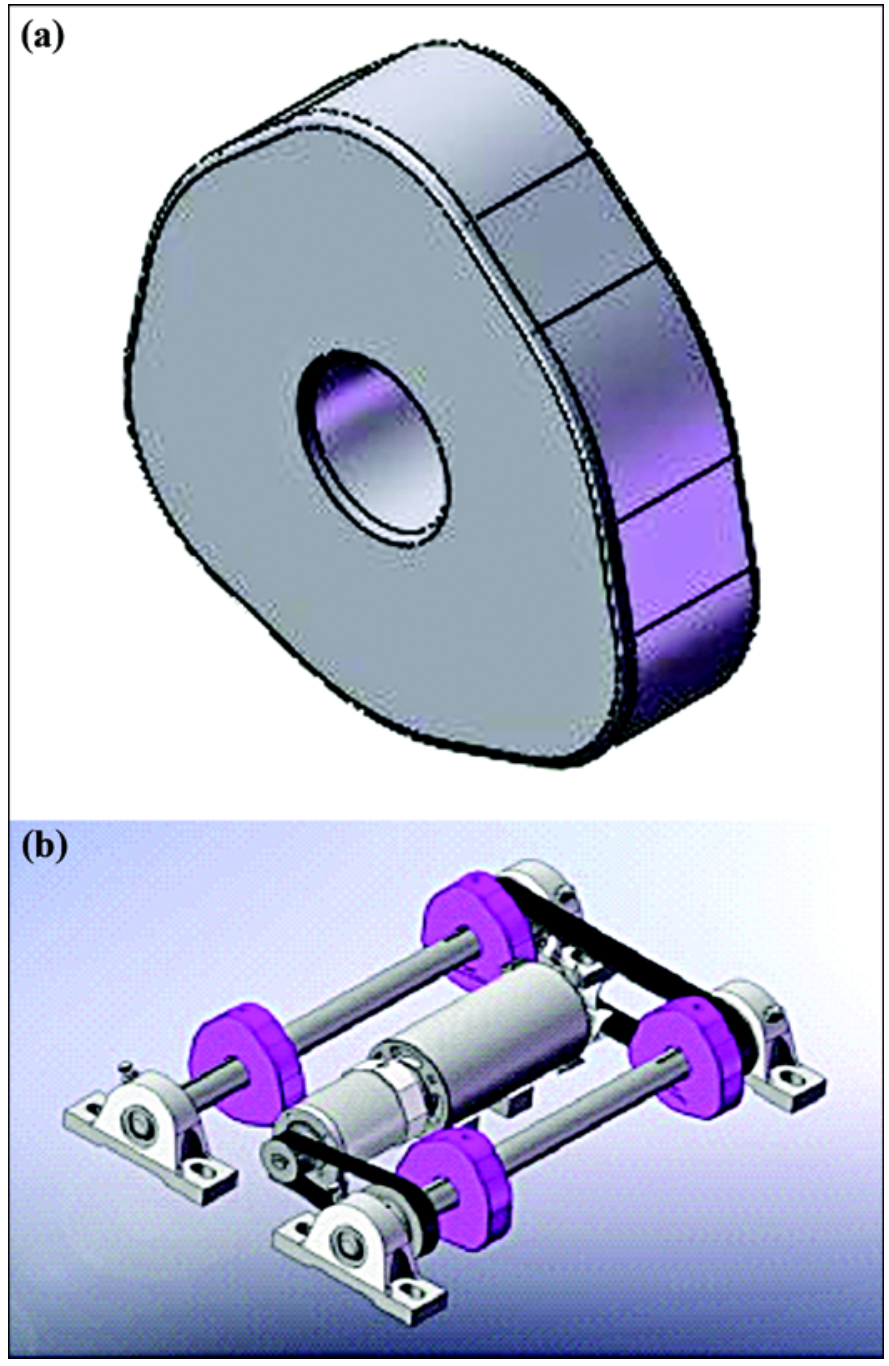

Figure 2.

(a) Specially designed cam geometry and (b) multiple vibration mechanism. 
operation. The vibrations of the platform are controlled by an electric motor. The rationale for asynchronous aligning cam peaks is to achieve different levels of impact force for facilitating muscle excitation and relaxation during platform operation. In action, the transitions from peaks to troughs and vice versa momentarily vary impact force intensities for controlling content of stimulation variable frequency.

The majority of cam vibration is in the vertical plane, with vertical displacement levels ranging from 1 to $6 \mathrm{~mm}$ for delivering upward stresses. At the same time, because of the asynchronous positions of the cams, they cause the platform to pitch and roll within an angular range from $0^{\circ}$ to $3^{\circ}$ in the medial-lateral and anteroposterior directions. As a result, a subject standing on the platform will experience the three motions (vertical oscillation, medial-lateral oscillation, and anteroposterior tilting) illustrated in Figure 3. The person will benefit from the vertically induced stresses and comfortable ankle joint and muscle exercises that are absent in strictly single-directional upward-motion modality.

\section{Computational Input Data}

The multiple vibration intensities of the device platform were acquired as input data for the computational simulation studies. To acquire platform acceleration in three directions ( $x$-, $y$ - and $z$-axes), we attached a triaxial accelerometer (ACL300 of Biometrics Ltd [NexGen Ergonomics, Inc; Pointe Claire, Quebec], sensitivity $\pm 100 \mathrm{mV} / \mathrm{G}$, and range $\pm 10 \mathrm{~g}$ ) at the center of the vibrating platform

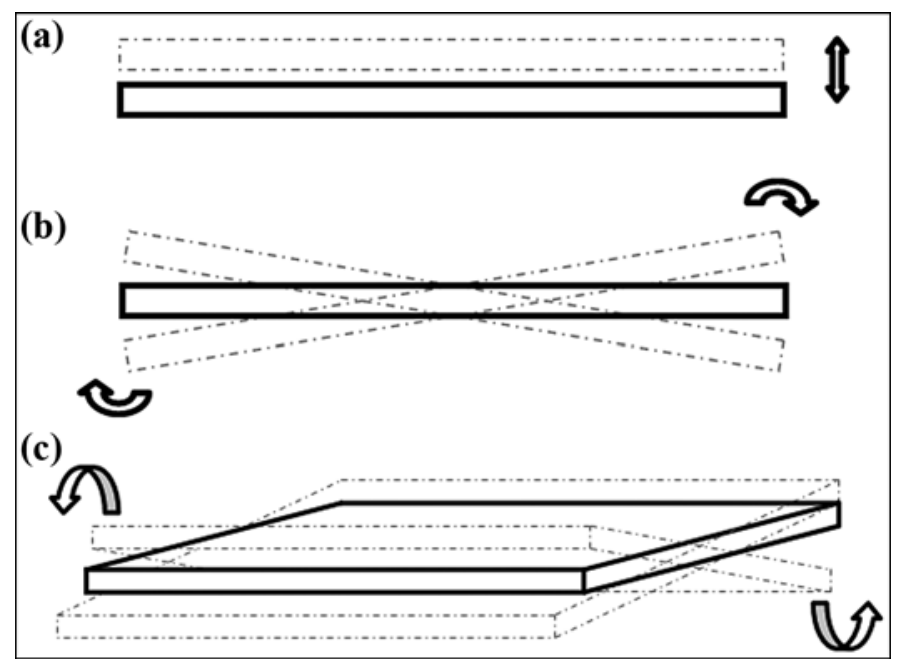

Figure 3.

Schematic drawing of multiple vibration displacements at multiple vibration frequencies platform motion: (a) vertical oscillation, (b) mediallateral oscillation, and (c) anteroposterior tilting. shown in Figure 1. We fed the signals from the accelerometer into a Biometrics DataLOG (No. W4X8 Bluetooth) to acquire $60 \mathrm{~s}$ of data. The signals were sampled at a sampling frequency of 1,000 Hz. After data collection, the data were imported directly into the Biometrics Display and Analysis Software. We then converted the data into acceleration using the built-in analysis software.

Figure 4 shows the signals recoded from the accelerometer, representing the vibration pattern of the device platform in the $x$-, $y$-, and $z$-directions for the duration of $0.5 \mathrm{~s}$. We used these data obtained from the accelerometer to derive the input force for the simulation study. They
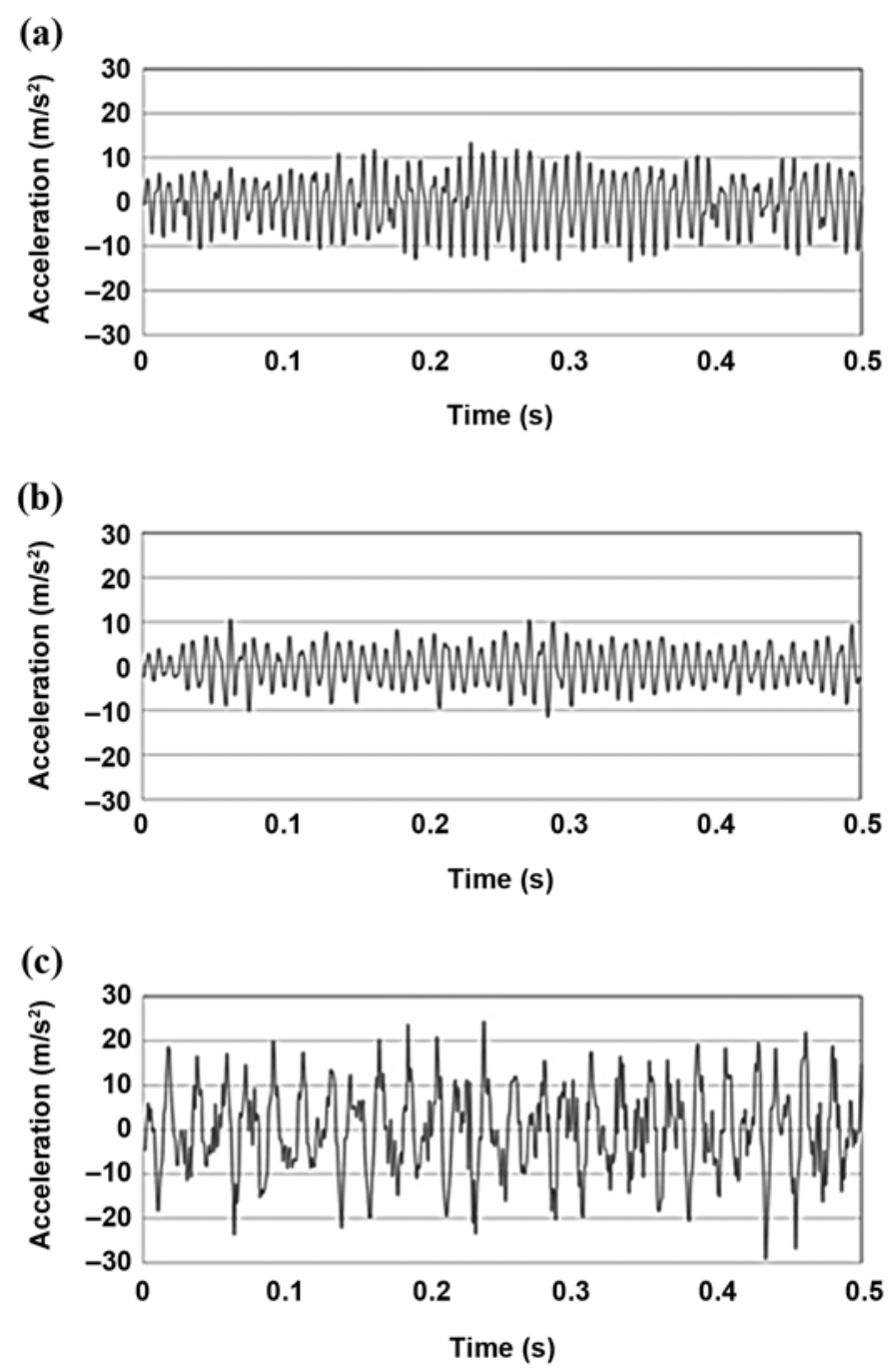

Figure 4.

Plot of platform acceleration profiles of device against time for duration of $0.5 \mathrm{~s}$ recording. Accelerations are shown in (a) $x$-, (b) $y$-, and (c) z-directions. 
represent the vibration stimulations transmitted to the body through the human interface system, the surface of the device platform. As expected, one can see that the acceleration intensities were greater in the $z$-direction compared with the intensities in the $x$ - and $y$-directions.

\section{Simulation Study}

The finite element technique used for the analysis is the stiffness method, where the displacements of the femur model in the vertical plane (z-axis) are unknown and the displacements of the femur in the $x$ - and $y$-axes are constrained. For this simulation study, the matrix forces were known and computed from the MVDMVF platform's $g$-values (expressed in gravitational terms) in the $z$-axis direction and the cam's displacement levels in z-axis. We then used the COMSOL Multiphysics (COMSOL, Inc; Burlington, Massachusetts) structural module computational solver to compute the stress flow along the femur.

To establish the finite element model, we created a solid model of the femur from the CT images of a male veteran subject in Mimics software by Materialise (Plymouth, Michigan). We used the analysis of the CT images in Mimics to separate the femur bone structure free of unwanted parts, such as muscle groups and other tissues not considered in this study. The triangular mesh of the model was generated on its surface. The model was then uploaded to COMSOL Multiphysics software for finite element analysis with the structural analysis module. The finite element model, as shown in Figure 5, consists of 18,604 elements with 5,052 nodes. The young modulus (E) was taken as $E=17 \mathrm{GPa}$ for cortical bone and $E=70$ MPa for cancellous bone [37]. The Poisson's ratio was set at 0.2 for cancellous bone and 0.3 for cortical bone. The material properties of the bone were assumed to be isotropic and linear elastic [38].

\section{Static Studies}

Two static stress scenarios were studied: first, with the subject standing on both legs and, second, was with the subject standing on one leg. For both scenarios, no vibration inputs were on the femur model for the statistic studies. The rationale for the static studies was to acquire stress baseline flow along the femur model for comparison with stress flow during dynamic studies. During the study, a preload vertical force of $350 \mathrm{~N}$ was imposed on the femur head. We adopted this loading condition to simulate the force transmitted through the femur when a person with a body weight of $85 \mathrm{~kg}$ (approximately $187 \mathrm{lb}$ ) is in the nor-

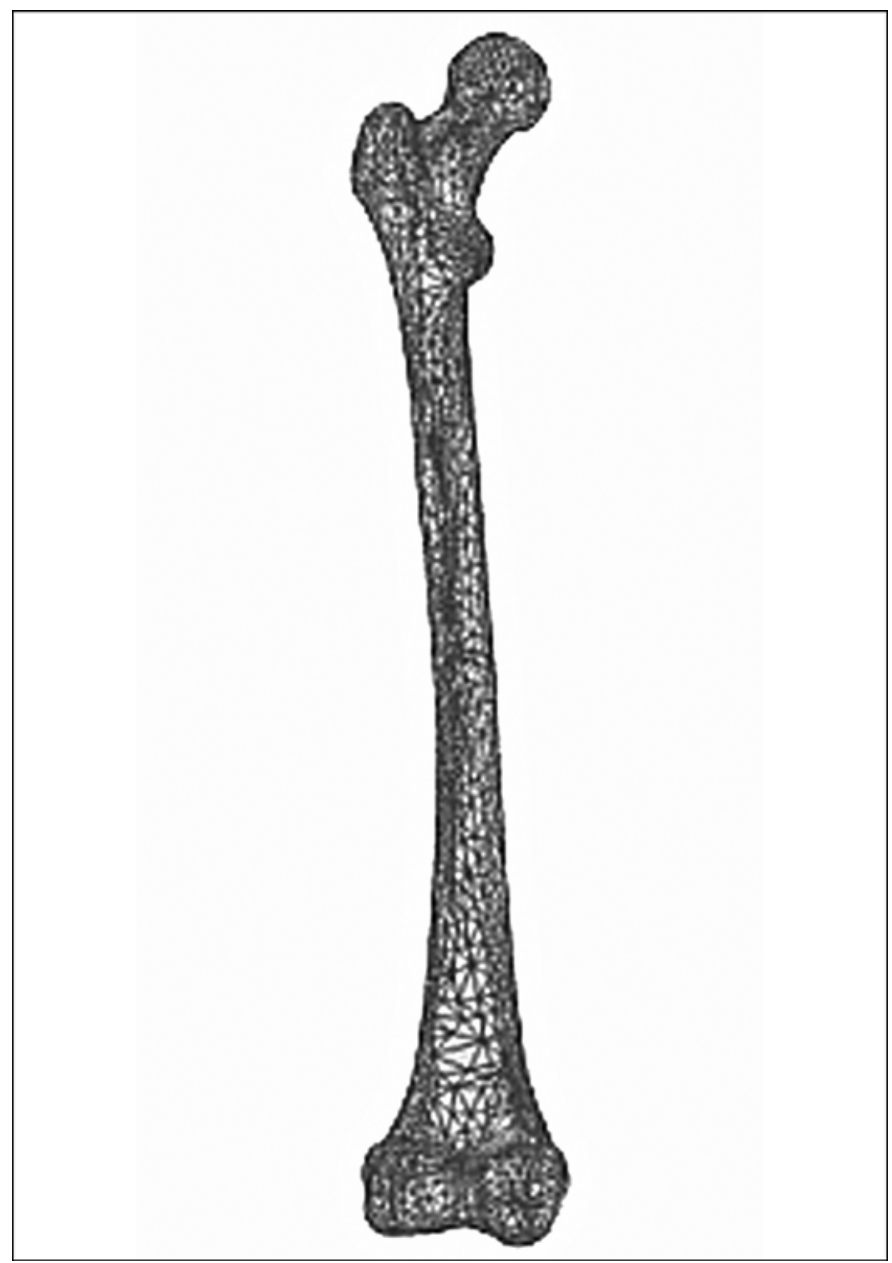

Figure 5.

Finite element mesh of femur model generated in Mimics (Materialise; Plymouth, Michigan) software for simulation study.

mal standing position after subtracting the weight of the leg, derived by the ratio of 0.161 to the body weight [39]. For the second scenario, we used the full body load (700 N), because of subject standing on one leg.

In COMSOL Multiphysics, the displacements in $x$ - and $y$-axes were constrained, allowing movement only in the $z$-direction. The constraints enabled us to study only the impact of MVDMVF vertically. We used the vibration displacements of the MVDMVF system with the vertical $g$-value to determine the impact force data set for the simulation studies. We did not apply the impact force data set at the distal end of the femur model to generate the stress distribution and levels during the simulation study. We analyzed the outcomes of the static simulation studies to determine the stress levels and flow pathways 
delivered without the MVDMVF intervention on the femur models.

\section{Dynamic Studies}

For the dynamic studies, the same constraints as in the static analysis in $x$ - and $y$-axes were imposed and movement only in the z-direction was used. We used the vibration displacements of the MVDMVF system with the vertical $g$-value to determine the impact force data set for the simulation studies. Four dynamic stress scenarios were studied: the first was the force input imposed by the load accelerating at $1.3 \mathrm{~g}$ in the $\mathrm{z}$-direction and a set of MVDMVF platform displacement levels ranging between 0.3 and $1.8 \mathrm{~mm}$. The second scenario is when the range is between 0.5 and $3.0 \mathrm{~mm}$, the third between 1 and $6 \mathrm{~mm}$, and the fourth between 2 and $12 \mathrm{~mm}$. We used the four derived input forces independently to apply input perturbation of the constrained femur during dynamic analysis. As in the static studies, a preload vertical force of $350 \mathrm{~N}$ was imposed on the femur head because the dynamic studies were conducted for a person standing on both legs.

As in static condition, the displacements in $x$ - and $y$-axis were constrained, allowing movement only in the $z$-direction. We applied each impact force data set at the distal end of the femur model to generate the stress distribution and levels during the simulation study. We analyzed the outcomes of the dynamic simulation studies to determine the stress levels and flow pathways delivered with the MVDMVF intervention on the femur models.

\section{RESULTS}

\section{Static Studies}

The outcomes of the static studies analysis of the model are presented in Figure 6. As illustrated in the Figure 6(a), peak stress at the femoral neck with the model standing on both legs with no vibration intervention had a magnitude of 16.6 MPa. In Figure 6(b), the peak stress at the femoral neck with the model standing on one leg with no vibration intervention had a magnitude of $42.1 \mathrm{MPa}$.

\section{Dynamic Studies}

The outcomes of the dynamic studies analysis of the model are presented in Figures $\mathbf{7}$ to $\mathbf{9}$. As illustrated in Figure 7, the four sets of input force resulted in different levels of stress on the femur with the first set for the displacement range between 0.3 and $1.8 \mathrm{~mm}$ as the mini-

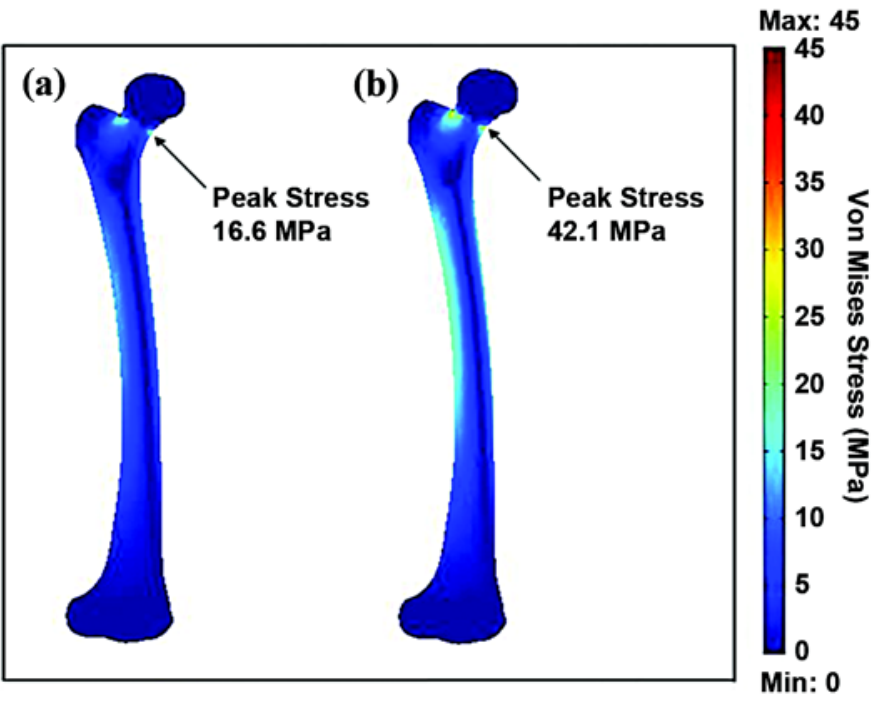

Figure 6.

COMSOL Multiphysics (COMSOL, Inc; Burlington, Massachusetts) results of static analysis of femur model: (a) normal standing (two legs), (b) one-legged standing.

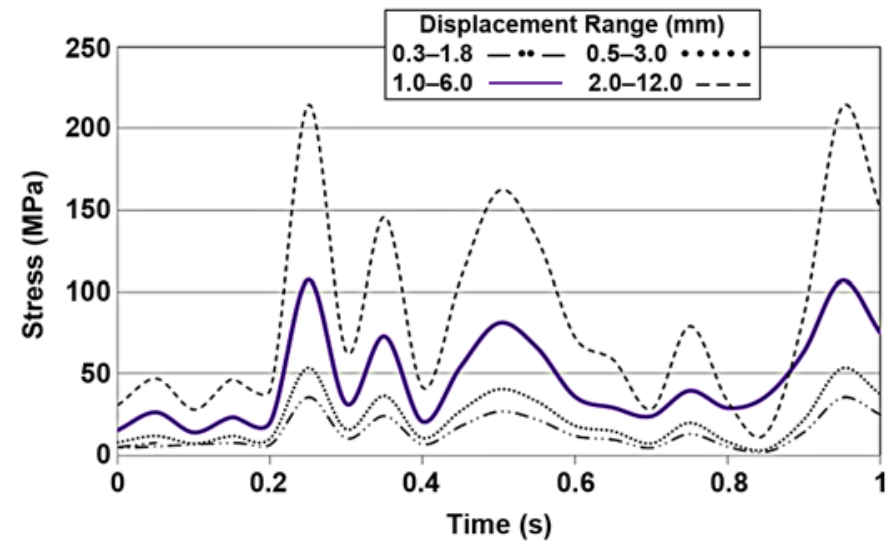

Figure 7.

Four sets of input force for displacement ranges that resulted in different stress levels on femur model.

mum. The second set for the displacement range between 0.5 and $3.0 \mathrm{~mm}$ was larger than the first. The third set between 1 and $6 \mathrm{~mm}$ was greater than the second set, and the fourth was the largest for the displacement range between 2 and $12 \mathrm{~mm}$. The results in Figure 7 show that the higher the vibration displacement, the higher the imposed stress on the femur.

Figure 8(a)-(d) shows the maximum impact stress on the femur for the four scenarios. The result shows that 


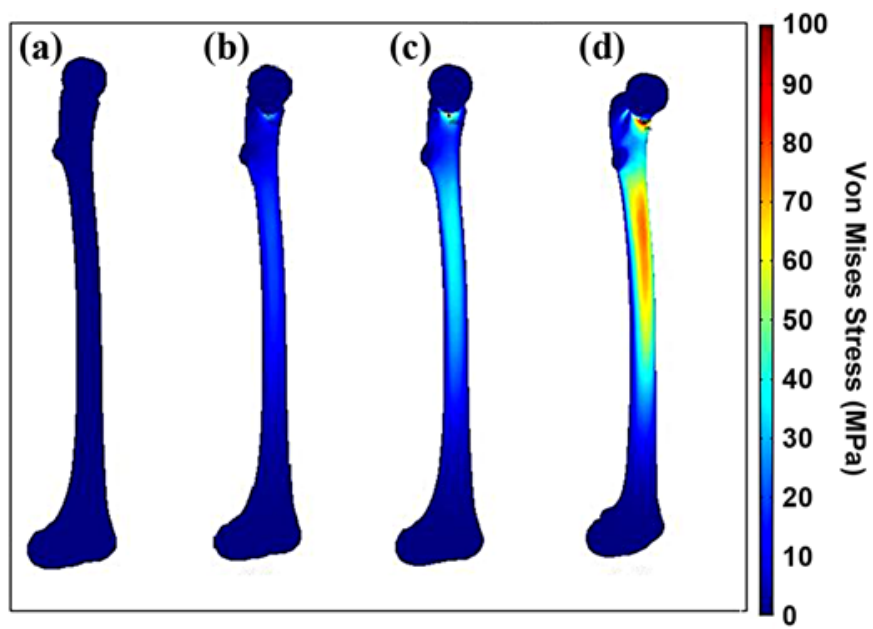

Figure 8.

Maximum stress levels of femur model: (a) 35.77, (b) 53.66 , (c) 107.30, and (d) 214.62 MPa.

stress levels progressively increased with the increase of the displacement level condition from Figure 8(a)-(d).

The stress distribution along the femur became more intense in Figure 8(c) 107.30 and (d) $214.62 \mathrm{MPa}$ and suggests intense load bearing. This excessive stress could be a problem for individuals with compromised bone strength. The results of peak values were then compared with published equivalent results for human activities during walking, stair-climbing and descending, and jogging. The results of the comparison show that the peak stress levels for Figure 8(a) 35.77 and (b) $53.66 \mathrm{MPa}$ were below equivalent levels for the published human activity levels. The peak stress level for Figure 8(c) was within the published value for stair-climbing and descending but below that of jogging. The peak level for Figure 8(d) was within and above the values during jogging. Thus, the outcome of this analysis suggests that MVDMVF displacement levels that are also equivalent to Figure 8(c) will be well tolerated by persons with compromised bone strength.

Figure 9(a)-(d) shows minimum stresses on the femur. The result shows that although stress levels progressively increased with increase in displacement level (Figure 9(a)-(d)), the stress distribution along the femur including the neck was not significantly high for all the conditions during walking, stair-climbing and descending, or jogging. This finding suggests that during the cyclic motion, the induced stress was low and provided brief relaxation time before the next cycle of maximum stress. This brief relaxation is particularly important because

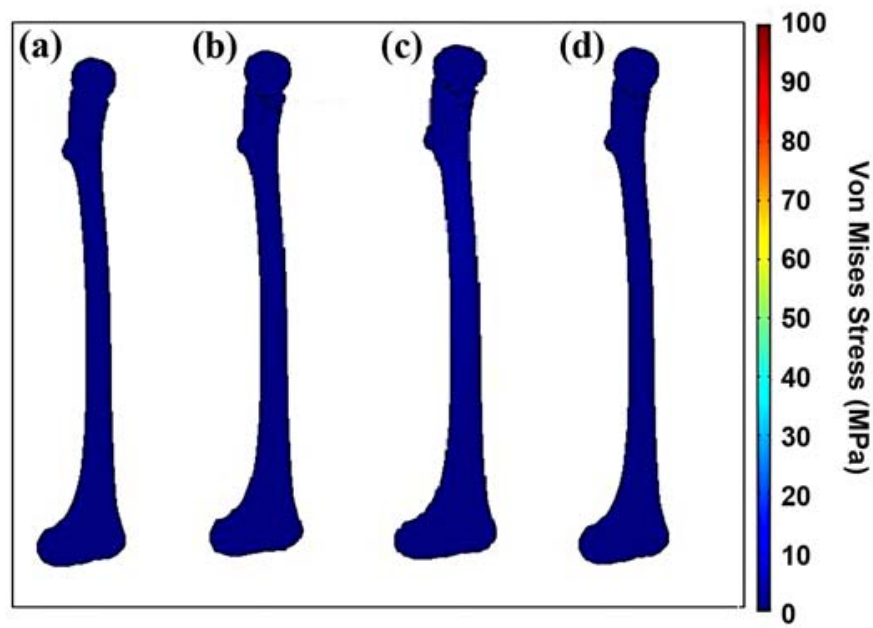

Figure 9.

Minimum stress levels of femur model: (a) 2.22, (b) 3.32, (c) 13.95, and (d) $13.29 \mathrm{MPa}$.

during repeated muscular excitation, brief relaxation time is necessary to prevent rapid muscle fatigue.

\section{DISCUSSION}

Understanding stress transmission in the skeletal system during vibration training is necessary for determining the load-bearing function and the efficacy of the vibration system. To the best of our knowledge, none of the published studies has determined the effects of vibration displacement levels on the human skeletal system for evaluating safety, especially those with compromised musculature and elderly persons. The lack of information may be due to the difficulty getting in vivo experiment results and difficulties in obtaining reliable muscle force data [40]. Therefore, this study considered only a simple femur model.

Safety is extremely important [41-43] when one considers the use of vibration training as a tool for bone strength improvement. Figure 4 shows the MVDMVF platform accelerations in the $x$-, $y$-, and z-directions from this study. The acceleration was highest in the $z$-direction, ranging from -20 to $20 \mathrm{~m} / \mathrm{s}^{2}$, and in the $x$ - and $y$-directions, ranging from -10 to $10 \mathrm{~m} / \mathrm{s}^{2}$. This unique platform acceleration pattern was designed to provide displacements in the vertical place and to pitch and roll movements to accommodate the floating nature of the anatomic ankle joint. To the best of our knowledge, none of the current available vibration training devices provides synchronous platform motions in more than one plane [44]. The root-mean-square values of the platform accelerations in 
the $x$-, $y$-, and $z$-directions are $0.6,0.4$, and $1.3 \mathrm{~g}$, respectively, which are within daily vibration exposure limits of published International Organization for Standardization (ISO) standard 2631-1 assessing the safety of vibration training [45].

From our simulation results, peak stress was located at the femoral neck. This finding generally agrees with published clinical studies and observations [46-47], as well as the feasibility single-subject test outcomes with the MVDMVF device published earlier [33]. In that study, a 79-year-old subject standing on the vibrating platform for two 15-minute vibration sessions per visit, three times a week, completed 60 visits. After the subject completed the vibration study, the postvibration BMD showed increase in BMD at the femoral neck compared with prestudy levels. This finding is important because previous studies have shown the importance of femoral neck BMD as a predictor of femur fracture and pressure accumulation [48-51]. Consequently, the present use of a realistic CT femur model provides important evidence of the stress level at the femur neck and is an appropriate method for evaluating the efficacy of MVDMVF for BMD improvement.

The limitation of the present study is that the effect of muscle contraction was not considered. The effect of muscle contraction will increase the level of applied load to the bone, and therefore, our results may underestimate stress. Also, since the material properties of soft tissue, such as ligament, tendon, and cartilage, were not considered, some of the magnitudes of the resulted stresses may have been overestimated, especially to the vibration input due to the damping effect of the tissue [52].

Despite recent advances in modeling, what stresses are generated within the proximal femur head and neck during physiological loading is still not clear [53]. Therefore, the present model should be considered as a preliminary attempt for developing a dynamic finite element model of the femur during moderate physical activity. Our results should be viewed in a comparative sense between the static and dynamic loading conditions. The development of a more complete dynamic model of the femur to include muscle and other soft tissue functions would lead to improved biomechanical understanding of the stress in the lower limbs. Once such a model is fully developed for computational analysis, improved biomechanical prediction of stress during vibration training would be possible. However, the intent of the simulation studies to demonstrate the differences between stress with and without
MVDMVF perturbation was achieved. The study also determined the displacement limits for safe use for the population with osteoporosis and elderly persons.

\section{CONCLUSIONS}

In this study, we analyzed the biomechanical responses of the femur under static and vibration loading using a three-dimensional CT femur model. The study results indicate (1) the MVDMVF vibration levels are within the daily vibration exposure limit standard set by ISO 2631-1 for assessing safety of vibration training and (2) that the MVDMVF device design philosophy achieved all intended purposes to deliver stress well within the normal physiological range of stress experienced during moderate physical activity. Additionally, the stress results agree with prior published data from outcomes of feasibility subject tests at equivalent anatomic joint locations. Since the feasibility subject outcomes demonstrated increased BMD, we anticipate future research in this area.

Further studies will expand the number of subjects to quantify the improvements in BMD, neuromuscular and cardiopulmonary responses, individual well-being, and overall function. Future simulation studies will use a more complete lower-limb model that includes both soft and hard tissue to determine a more complete simulation outcome.

\section{ACKNOWLEDGMENTS}

\section{Author Contributions:}

Study concept and design: B. Ezenwa.

Acquisition of data: H. T. Yeoh, B. Ezenwa.

Analysis and interpretation of data: B. Ezenwa, H. T. Yeoh.

Drafting of manuscript: B. Ezenwa, H. T. Yeoh.

Critical revision of manuscript for important intellectual content:

B. Ezenwa.

Statistical analysis: B. Ezenwa.

Obtained funding: B. Ezenwa.

Administrative, technical, or material support: B. Ezenwa.

Study supervision: B. Ezenwa.

Financial Disclosures: The authors have declared that no competing interests exist.

Funding/Support: This material is the result of work supported with resources and the use of facilities at the University of Wisconsin System Foundation, Madison, Wisconsin.

Additional Contribution: Dr. Ezenwa is now with the University of Wisconsin-Stout Discovery Center in Menomonie, Wisconsin.

Institutional Review: We obtained institutional review board approval from the University of Wisconsin-Milwaukee, Milwaukee, Wisconsin. 
Participant Follow-Up: The authors do not plan to inform participant of the publication of this study. However, participant has been encouraged to check the study Web site for updated publications.

\section{REFERENCES}

1. Tosteson AN, Hammond CS. Quality-of-life assessment in osteoporosis: Health-status and preference-based measures. Pharmacoeconomics. 2002;20(5):289-303. [PMID: 11994039] DOI:10.2165/00019053-200220050-00001

2. Lips P, Van Schoor NM. Quality of life in patients with osteoporosis. Osteoporos Int. 2005;16(5):447-55.

[PMID: 15609073$]$

DOI:10.1007/s00198-004-1762-7

3. Gold DT. The nonskeletal consequences of osteoporotic fractures. Psychologic and social outcomes. Rheum Dis Clin North Am. 2001;27(1):255-62. [PMID: 11285999] DOI:10.1016/S0889-857X(05)70197-6

4. Adachi JD, Ioannidis G, Pickard L, Berger C, Prior JC, Joseph L, Hanley DA, Olszynski WP, Murray TM, Anastassiades T, Hopman W, Brown JP, Kirkland S, Joyce C, Papaioannou A, Poliquin S, Tenenhouse A, Papadimitropoulos EA. The association between osteoporotic fractures and health-related quality of life as measured by the Health Utilities Index in the Canadian Multicentre Osteoporosis Study (CaMos). Osteoporos Int. 2003;14(11):895-904.

[PMID: 12920507]

DOI:10.1007/s00198-003-1483-3

5. Boonen S, Dejaeger E, Vanderschueren D, Venken K, Bogaerts A, Verschueren S, Milisen K. Osteoporosis and osteoporotic fracture occurrence and prevention in the elderly: A geriatric perspective. Best Pract Res Clin Endocrinol Metab. 2008;22(5):765-85. [PMID: 19028356] DOI:10.1016/j.beem.2008.07.002

6. Lüthje P, Nurmi-Lüthje I, Kaukonen JP, Kuurne S, Naboulsi H, Kataja M. Undertreatment of osteoporosis following hip fracture in the elderly. Arch Gerontol Geriatr. 2009;49(1):153-57. [PMID: 18706704$]$

DOI:10.1016/j.archger.2008.06.007

7. Burge R, Dawson-Hughes B, Solomon DH, Wong JB, King A, Tosteson A. Incidence and economic burden of osteoporosisrelated fractures in the United States, 2005-2025. J Bone Miner Res. 2007;22(3):465-75. [PMID: 17144789]

DOI:10.1359/jbmr.061113

8. Steinberg EL, Blumberg N, Dekel S. The fixion proximal femur nailing system: Biomechanical properties of the nail and a cadaveric study. J Biomech. 2005;38(1):63-68. [PMID: 15519340]

9. Rizzoli R, Bruyere O, Cannata-Andia JB, Devogelaer JP, Lyritis G, Ringe JD, Vellas B, Reginster JY. Management of osteoporosis in the elderly. Curr Med Res Opin. 2009;
25(10):2373-87. [PMID: 19650751]

DOI:10.1185/03007990903169262

10. Marks R, Guertin D. Postmenopausal osteoporosis and aerobic exercise: A review of the literature. Curr Rheumatol Rev. 2006;2(3):289-301. DOI:10.2174/157339706778019638

11. Kenny AM, Smith J, Noteroglu E, Waynik IY, Ellis C, Kleppinger A, Annis K, Dauser D, Walsh S. Osteoporosis risk in frail older adults in assisted living. J Am Geriatr Soc. 2009;57(1):76-81. [PMID: 19054182] DOI:10.1111/j.1532-5415.2008.02072.x

12. Rubin C, Turner AS, Bain S, Mallinckrodt C, McLeod K. Anabolism. Low mechanical signals strengthen long bones. Nature. 2001;412(6847):603-4. [PMID: 11493908] DOI:10.1038/35088122

13. Rubin C, Turner AS, Müller R, Mittra E, McLeod K, Lin W, Qin YX. Quantity and quality of trabecular bone in the femur are enhanced by a strongly anabolic, noninvasive mechanical intervention. J Bone Miner Res. 2002;17(2): 349-57. [PMID: 11811566] DOI:10.1359/jbmr.2002.17.2.349

14. Iwamoto J, Takeda T, Sato Y, Uzawa M. Effect of wholebody vibration exercise on lumbar bone mineral density, bone turnover, and chronic back pain in postmenopausal osteoporotic women treated with alendronate. Aging Clin Exp Res. 2005;17(2):157-63. [PMID: 15977465]

15. Semler O, Fricke O, Vezyroglou K, Stark C, Stabrey A, Schoenau E. Results of a prospective pilot trial on mobility after whole body vibration in children and adolescents with osteogenesis imperfecta. Clin Rehabil. 2008;22(5):387-94. [PMID: 18441035] DOI:10.1177/0269215507080763

16. Cardinale M, Rittweger J. Vibration exercise makes your muscles and bones stronger: Fact or fiction? J Br Menopause Soc. 2006;12(1):12-18. [PMID: 16513017] DOI:10.1258/136218006775997261

17. Torvinen S, Kannus P, Sievänen H, Järvinen TA, Pasanen M, Kontulainen S, Järvinen TL, Järvinen M, Oja P, Vuori I. Effect of four-month vertical whole body vibration on performance and balance. Med Sci Sports Exerc. 2002;34(9): 1523-28. [PMID: 12218749] DOI:10.1097/00005768-200209000-00020

18. Bogaerts A, Verschueren S, Delecluse C, Claessens AL, Boonen S. Effects of whole body vibration training on postural control in older individuals: A 1-year randomized controlled trial. Gait Posture. 2007;26(2):309-16.

[PMID: 17074485]

DOI:10.1016/j.gaitpost.2006.09.078

19. Torvinen S, Kannus P, Sievänen H, Järvinen TA, Pasanen M, Kontulainen S, Järvinen TL, Järvinen M, Oja P, Vuori I. Effect of a vibration exposure on muscular performance and body balance. Randomized cross-over study. Clin Physiol 
Funct Imaging. 2002;22(2):145-52. [PMID: 12005157] DOI:10.1046/j.1365-2281.2002.00410.x

20. Bautmans I, Van Hees E, Lemper J, Mets T. The feasibility of Whole Body Vibration in institutionalised elderly persons and its influence on muscle performance, balance and mobility: A randomised controlled trial [ISRCTN62535013]. BMC Geriatr. 2005;5:17. [PMID: 16372905]

DOI:10.1186/1471-2318-5-17

21. Yamada E, Kusaka T, Miyamoto K, Tanaka S, Morita S, Tanaka S, Tsuji S, Mori S, Norimatsu H, Itoh S. Vastus lateralis oxygenation and blood volume measured by near-infrared spectroscopy during whole body vibration. Clin Physiol Funct Imaging. 2005;25(4):203-8. [PMID: 15972021] DOI:10.1111/j.1475-097X.2005.00614.X

22. Lythgo N, Eser P, De Groot P, Galea M. Whole-body vibration dosage alters leg blood flow. Clin Physiol Funct Imaging. 2009;29(1):53-59. [PMID: 19125731]

DOI:10.1111/j.1475-097X.2008.00834.X

23. Lohman EB 3rd, Petrofsky JS, Maloney-Hinds C, BettsSchwab H, Thorpe D. The effect of whole body vibration on lower extremity skin blood flow in normal subjects. Med Sci Monit. 2007;13(2):CR71-76. [PMID: 17261985$]$

24. Rees SS, Murphy AJ, Watsford ML. Effects of whole-body vibration exercise on lower-extremity muscle strength and power in an older population: A randomized clinical trial. Phys Ther. 2008;88(4):462-70. [PMID: 18218826] DOI:10.2522/ptj.20070027

25. Tihanyi TK, Horváth M, Fazekas G, Hortobágyi T, Tihanyi $\mathrm{J}$. One session of whole body vibration increases voluntary muscle strength transiently in patients with stroke. Clin Rehabil. 2007;21(9):782-93. [PMID: 17875558] DOI:10.1177/0269215507077814

26. Bogaerts A, Delecluse C, Claessens AL, Coudyzer W, Boonen S, Verschueren SM. Impact of whole-body vibration training versus fitness training on muscle strength and muscle mass in older men: A 1-year randomized controlled trial. J Gerontol A Biol Sci Med Sci. 2007;62(6):630-35. [PMID: 17595419]

27. Roelants M, Delecluse C, Verschueren SM. Whole-bodyvibration training increases knee-extension strength and speed of movement in older women. J Am Geriatr Soc. 2004; 52(6):901-8. [PMID: 15161453] DOI:10.1111/j.1532-5415.2004.52256.X

28. Van den Tillaar R. Will whole-body vibration training help increase the range of motion of the hamstrings? J Strength Cond Res. 2006;20(1):192-96. [PMID: 16503680] DOI:10.1016/j.ptsp.2006.11.003

29. Rønnestad BR. Acute effects of various whole-body vibration frequencies on lower-body power in trained and untrained subjects. J Strength Cond Res. 2009;23(4):1309-15. [PMID: 19568035]
30. Moras G, Tous J, Muñoz CJ, Padullés JM, Vallejo L. Electromyographic response during whole-body vibrations of different frequencies with progressive external loads [Internet]; 2006 Feb. Buenos Aires (Argentina): Revista Digital; c1997-2006 [cited 2010 Dec 17]. Available from: http://www.efdeportes.com/efd93/emg.htm.

31. Da Silva ME, Nuñez VM, Vaamonde D, Fernandez JM, Poblador MS, Garcia-Manso JM, Lancho JL. Effects of different frequencies of whole body vibration on muscular performance. Biol Sport. 2006;23(3):267-81.

32. Sargeant AJ. Structural and functional determinants of human muscle power. Exp Physiol. 2007;92(2):323-31. [PMID: 17255174] DOI:10.1113/expphysiol.2006.034322

33. Ezenwa B, Burns E, Wilson C. Multiple vibration intensities and frequencies for bone mineral density improvement. Conf Proc IEEE Eng Med Biol Soc. 2008;2008:4186-89. [PMID: 19163635$]$

34. Gefen A. Consequences of imbalanced joint-muscle loading of the femur and tibia: From bone cracking to bone loss. Proceedings of the 25th Annual International Conference of the IEEE Engineering in Medicine and Biology Society; 2003 Sep 17-21; Cancun, Mexico. p. 1827-30.

35. Madou KH, Cronin JB. The effects of whole body vibration on physical and physiological capability in special populations. Hong Kong Physiother J. 2008;26:24-38. DOI:10.1016/S1013-7025(09)70005-3

36. Cowin SC, editor. Bone mechanics handbook. Boca Raton (FL): CRC Press; 2001. ISBN: 0-8493-9117-2.

37. Yuehuei AH. Mechanical properties of bone. In: Yuehuei HA, Draughn RA, editors. Mechanical testing of bone and the bone-implant interface. Boca Raton (FL): CRC Press; 1999. p. 41-63.

38. Saltzman WM. Tissue engineering: Engineering principle for design of replacement organs and tissues. New York (NY): Oxford University Press; 2004. 121 p.

39. Iglic A, Kralj-Iglic V, Daniel M, Macek-Lebar A. Computer determination of contact stress distribution and the size of the weight-bearing area in the human hip joint. Comput Methods Biomech Biomed Engin. 2002;5(2):185-92. [PMID: 12186728] DOI:10.1080/10255840290010300

40. Polgár K, Gill HS, Viceconti M, Murray DW, O’Connor JJ. Strain distribution within the human femur due to physiological and simplified loading: Finite element analysis using the muscle standardized femur model. Proc Inst Mech Eng H. 2003;217(3):173-89. [PMID: 12807158] DOI:10.1243/095441103765212677

41. Rubin C, Pope M, Fritton JC, Magnusson M, Hansson T, McLeod K. Transmissibility of 15 -hertz to 35 -hertz vibrations to the human hip and lumbar spine: Determining the physiologic feasibility of delivering low-level anabolic mechanical 
stimuli to skeletal regions at greatest risk of fracture because of osteoporosis. Spine (Phila Pa 1976). 2003; 28(23):2621-27. [PMID: 14652479]

42. Abercromby AF, Amonette WE, Layne CS, McFarlin BK, Hinman MR, Paloski WH. Vibration exposure and biodynamic responses during whole-body vibration training. Med Sci Sports Exerc. 2007;39(10):1794-1800. [PMID: 17909407] DOI:10.1249/mss.0b013e3181238a0f

43. Mester J, Kleinöder H, Yue Z. Vibration training: Benefits and risks. J Biomech. 2006;39(6):1056-65. [PMID: 15869759] DOI:10.1016/j.jbiomech.2005.02.015

44. Pel JJ, Bagheri J, Van Dam LM, Van den Berg-Emons HJ, Horemans HL, Stam HJ, Van der Steen J. Platform accelerations of three different whole-body vibration devices and the transmission of vertical vibrations to the lower limbs. Med Eng Phys. 2009;31(8):937-44. [PMID: 19523867] DOI:10.1016/j.medengphy.2009.05.005

45. ISO 2631-1: 1997. Mechanical vibration and shock-Evaluation of human exposure to whole body vibration. Part 1: General requirements. Geneva (Switzerland): International Organization for Standardization; 1997.

46. Voo L, Armand M, Kleinberger M. Stress fracture risk analysis of the human femur based on computational biomechanics. Johns Hopkins APL Tech Dig. 2004;25(3):223-30.

47. Little JP, Taddei F, Viceconti M, Murray DW, Gill HS. Changes in femur stress after hip resurfacing arthroplasty: Response to physiological loads. Clin Biomech (Bristol, Avon). 2007;22(4):440-48. [PMID: 17257719] DOI:10.1016/j.clinbiomech.2006.12.002

48. Alonso CG, Curiel MD, Carranza FH, Cano RP, Peréz AD. Femoral bone mineral density, neck-shaft angle and mean femoral neck width as predictors of hip fracture in men and women. Projects for research in osteoporosis. Osteoporos Int. 2000;11(8):714-20. [PMID: 11095176] DOI:10.1007/s001980070071

49. Bergot C, Bousson V, Meunier A, Laval-Jeantet M, Laredo JD. Hip fracture risk and proximal femur geometry from DXA scans. Osteoporos Int. 2002;13(7):542-50. [PMID: 12111014$]$ DOI:10.1007/s001980200071

50. Gnudi S, Ripamonti C, Lisi L, Fini M, Giardino R, Giavaresi G. Proximal femur geometry to detect and distinguish femoral neck fractures from trochanteric fractures in postmenopausal women. Osteoporos Int. 2002;13(1):69-73.

[PMID: 11878458] DOI:10.1007/s198-002-8340-2

51. Kukla C, Gaebler C, Pichl RW, Prokesch R, Heinze G, Heinz T. Predictive geometric factors in a standardized model of femoral neck fracture: Experimental study of cadaveric human femurs. Injury. 2002;33(5):427-33.

[PMID: 12095724$]$

DOI:10.1016/S0020-1383(02)00076-1

52. Kiiski J, Heinonen A, Järvinen TL, Kannus P, Sievänen H. Transmission of vertical whole body vibration to the human body. J Bone Miner Res. 2008;23(8):1318-25.

[PMID: 18348698]

DOI:10.1359/jbmr.080315

53. Rudman KE, Aspden RM, Meakin JR. Compression or tension? The stress distribution in the proximal femur. Biomed Eng Online. 2006;5:12. [PMID: 16504005]

DOI:10.1186/1475-925X-5-12

Submitted for publication May 18, 2010. Accepted in revised form October 7, 2010.

This article and any supplementary material should be cited as follows:

Ezenwa B, Yeoh HT. Multiple vibration displacements at multiple vibration frequencies stress impact on human femur computational analysis. J Rehabil Res Dev. 2011; 48(2):179-90.

DOI:10.1682/JRRD.2010.05.0096

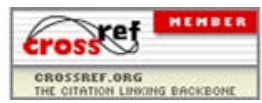


